\title{
An intrathoracic lipoma impairing left ventricular function
}

\author{
Catherine I A Jack, Martin E G Blohm, Michael Lye
}

Department of Geriatric Medicine, Royal Liverpool Hospital, Liverpool C I A Jack M E G Blohm $M$ Lye

Correspondence to: Dr C I A Jack, Department of Geriatric Medicine, University of Liverpool, PO Box 147, Liverpool L69 3BX.

Accepted for publication 1 February 1995.
An 81 year old man presented with dyspnoea. On examination he had bilateral basal crackles and peripheral pitting oedema. On the left lateral chest wall there was a firm, non-tender subcutaneous mass $(5 \mathrm{~cm}$ in diameter). The patient claimed that this had been present for 15 years and had not grown.

The chest radiograph showed left basal consolidation and pulmonary oedema. The initial diagnosis was pneumonia with left ventricular failure. The patient improved with antibiotic and diuretic therapy. Echocardiography revealed a large echodense mass adjacent to but separate from the left ventricle, impairing its function.Computed tomography confirmed a large intrathoracic cyst alongside the left ventricle which seemed to communicate with the extrathoracic cyst on the left lateral chest wall (figure). The patient refused further intervention. On discharge his cardiac failure was well controlled but unfortunately he suddenly collapsed and died at home.

Necropsy confirmed a subcutaneous lipoma on the chest wall. Within the left thoracic cavity there was a separate lipoma measuring $19 \times 11 \times 9 \mathrm{~cm}$. The heart was otherwise normal.
Intrathoracic lipomas were first described in 1783. ${ }^{1}$ Thoracic lipomas are usually asymptomatic and best detected by computed tomography or magnetic resonance imaging. ${ }^{2}$ The possibility of a liposarcoma should be considered if the mass is not of uniform density on scanning. ${ }^{3}$ In our case the intrathoracic lipoma was detected only on the echocardiogram. Cardiac lipomas account for $8.4 \%$ of all cardiac tumours. ${ }^{4}$ Pericardial lipomas have also been reported. As far as we are aware, this is the first reported case of an intrathoracic, extrapericardial lipoma presenting as left ventricular dysfunction. Several cases of successful surgical resection of thoracic lipomata have been reported ${ }^{5}$ but our patient would not consider any intervention.

1 Fothergill J. Cited by Sulzer et al. Lipoma of the external thoracic wall. Eur Respir F 1994;7:207-9.

2 Buxton RC, Tan CS, Khine NM, Cusay NS, Shor MJ, Spigos DG. Atypical transmural thoracic lipoma: CT Diagnosis. F Comput Assist Tomogr 1988;12:196-8.

3 Epler GR, McLoud TC, Munn CS, Colby TV. Pleural lipoma: diagnosis by computed tomography. Chest 1986; 90:265-8.

4 Kunjlata A, van Hoeven KH. Fatal lipoma of the heart. Am F Cardiovasc Pathol 1992;4:85-90.

5 Akiyama S, Kataoka M, Horisawa M, Inoue S, Sakai M, Ito $\mathrm{K}$, et al. Lipoma of the esophagus-Report of a case and review of the literature. $f_{p n} \mathcal{f}$ Surgery 1990;20: 458-62.

$C T$ scan showing the lesion extending from the mediastinum to the thoracic wall. On this section the lesion seems to communicate with the extrathoracic lipoma. There is a small right pleural effusion.

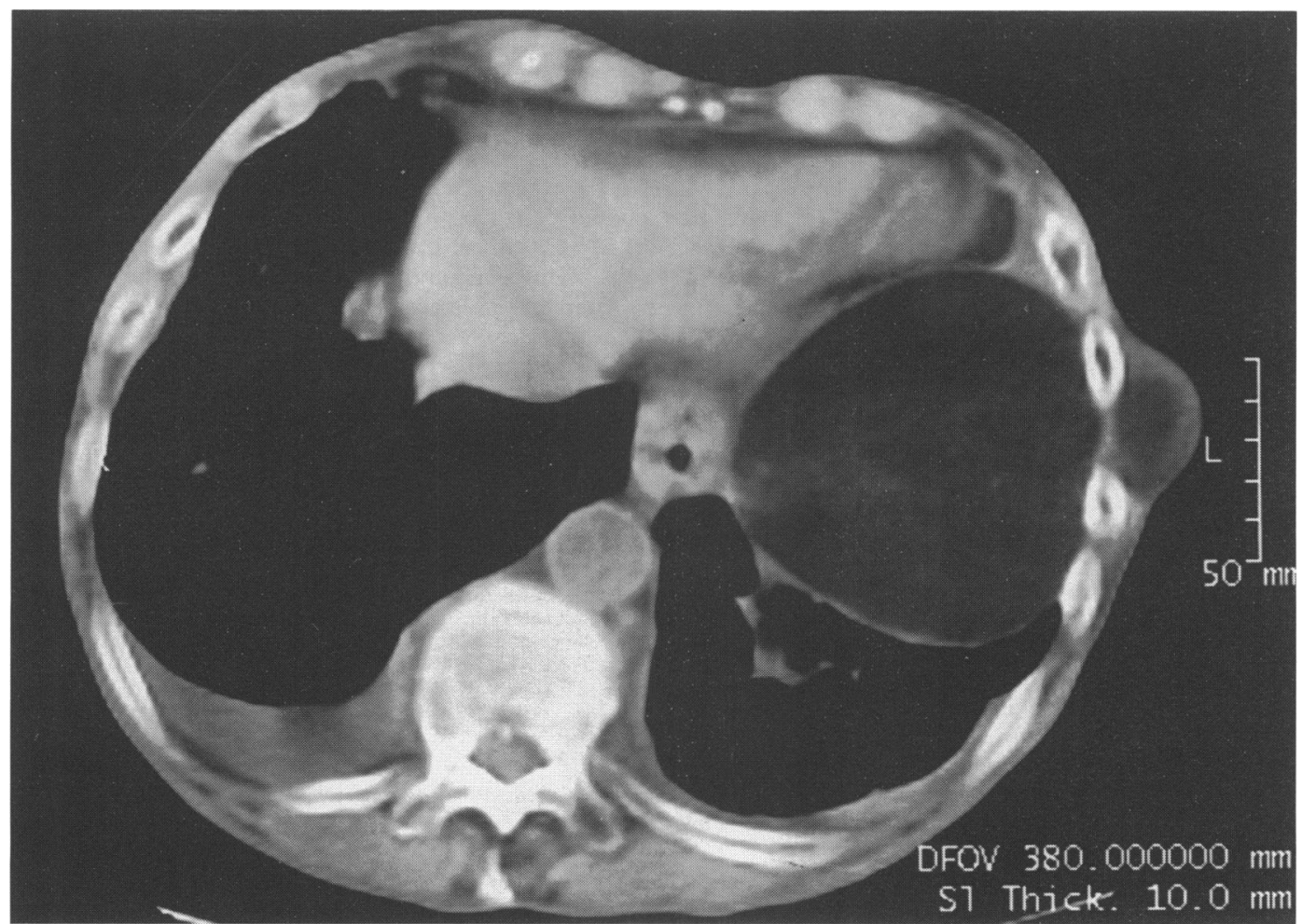

